\title{
Development of Mobile and Computer Website Integrated College Content Management System
}

\author{
Zhidan Yang ${ }^{a}$, Chunpeng $\mathrm{Li}^{\mathrm{b}}$, Simeng Chen \\ TSL School of Business and Information Technology, Quanzhou Normal University, Quanzhou, \\ 362000, China \\ aemail: 15959874421@163.com, bemail:chunpeng-li@163.com
}

\begin{abstract}
Keywords: Content Management System; Mobile Website; College Website
\end{abstract}
\begin{abstract}
The current number of mobile Internet users has far exceeded the number of PC Internet users. The construction of college mobile website is behind the PC website. An innovative idea which integrates mobile website and computer website into one system was proposed. Content management technology is used in the system. The system which mobile website and computer website integrates into college online content management system is developed. It allows colleges and universities to build the mobile and computer website at the same time. The construction and management of integration meets the needs of smartphone and computer access. The system would enhance the level of college information.
\end{abstract}

\section{Concept of College Content Management System}

Content Management System has back-office systems or processes between software systems. Content Management System focused on solving a variety of unstructured or semi-structured collection of digital resources. It can be integrated into structured data organic business intelligence environments, such as OA, CRM, etc. Content creators, editors, publishers use content management system to submit, and publish content. The "content" may include all information files, tables, pictures, and data in the database or video.

Content Management System is used in college website building software industry establishment. College website content management system can simplify the construction, management and maintenance. The basic idea is to achieve the appearance and content of the separation and management. Content Management System is stored in a database or file system. The appearance of the page is to use a template to achieve. When a user requests a page, the page has a standard HTML page provided to the user. To browse through the use of templates, administrators only need to modify the template and feel of the site adjustment. Managers can focus on content design, and greatly simplify site management and maintenance.

\section{Background of Mobile and Computer Website Integrated College Content Management System}

After more than a decade of e-commerce development, it begins to take shape from the bud growth industry, network operators, network companies, online banking, mobile terminals and other specialized services. They have become the leading modern services development of new industries. In January 16, 2014, the China Internet Network Information Center released in Beijing 33rd "Statistical Report on Internet Development in China". In December 2013, Chinese reached 618 million, Internet penetration. Among them, the scale of mobile phone users reached 500 million. It continues to maintain steady growth. Mobile phone users have promoted the development of various types of mobile terminal applications. It has become a major highlight of the 2013 China Internet development.

4G technology is universal. Mobile e-commerce era will gradually insert into our lives. Mobile Internet has become the main way for Internet users. Mobile website and computer website integration are in the development trend of current college website. It has information technology, 
digital campus project and indispensable link. The construction of the campus network is constantly expanding. Currently only $90 \%$ of colleges and universities can establish computer website. The current number of mobile Internet users has far exceeded the number of computers of Internet users, while mobile site overlooked are most colleges and universities. Mobile website construction tends to behind the computer website. Urgently requires universities to create a site mobile website. Development of mobile and computer website integrated college online content management system. It enables mobile phone and computer website construction and management of synchronization, integration. The needs of computer access, mobile phone users are an important aspect of the college website.

\section{Development Status and Trends of College Content Management System}

Development of data management in the college website, roughly through three stages: static updates, real-time updates, CMS management. You can clearly see the website compare data management experienced three stages. Their characteristics have some simple. From the table, we can see that college content management system is in the development trend of college construction site.

Table 1 college website data management stages of development

\begin{tabular}{|l|l|l|}
\hline \multicolumn{1}{|c|}{$\begin{array}{c}\text { Development } \\
\text { Stage }\end{array}$} & \multicolumn{1}{|c|}{ Stage Name } & \multicolumn{1}{c|}{ Stage Features } \\
\hline The first stage & Static Update & $\begin{array}{l}\text { Manually update static publishing, no interaction, } \\
\text { load small }\end{array}$ \\
\hline The second stage & Live Update & $\begin{array}{l}\text { Automatic updates, dynamic publishing, interactive, } \\
\text { load, difficult to extend sharing }\end{array}$ \\
\hline The third stage & $\begin{array}{l}\text { Content } \\
\text { Management }\end{array}$ & $\begin{array}{l}\text { Automatic updates, dynamic publishing, interactive, } \\
\text { load is small, easy to extend sharing }\end{array}$ \\
\hline
\end{tabular}

At present, web content management system still has many imperfections. Yet a college website content management system is appearing. Currently there is no content management system for the design and optimization of mobile Internet. Mobile Internet users are not conducive to the content browsing, sharing and promotion. There is an urgent need to develop a mobile phone and computer website. It integrated management college system. Colleges and universities can solve the drawbacks of the current construction site.

\section{Application Value of Mobile and Computer Website Integrated College Content Management System}

Current phone website has become the main entrance to many users. The traditional college website in the phone stands delayed construction defects. Mobile and computer website integrated college online content management system. Through it we can solve the problem lacking traditional college website construction. To all levels of college Web site, you can easily use the system to create a site. The template technology can easily complete revision of the work site, mobile and computer website integrated applications. The needs of mobile phones and computers can access the Internet users, thus speeding up the college information building. This will bring huge benefits to China's economic and society. It is showed in the following aspects.

Economic functions:

(1) The application of mobile and computer website integrated information technology makes the site construction become easier. Mobile phone users and PC users, significantly enhance the user experience, so as to achieve the purpose of the construction site.

(2) Mobile and computer website integrated online content management system. Content 
management can achieve synchronization.

(3) Mobile and computer website integrated college online content management system is widely used to help colleges and universities reduce site construction. Management, maintenance, marketing costs, speed up the process of information in colleges and universities.

Social functions:

(1) The system adapts to the mobile, digital, trends in information technology universities. The implementation of this system allows construction of college site. Mobile and computer website are more convenient.

(2) Construction of College system makes use of the mobile phone and computer website sites, maintenance easier. The site content is also more susceptible to computer users and mobile phone users to browse. We can enhance the user experience and improve the application of the effect site. The construction and management of college information rose to a new level of application.

\section{Key Technologies to Realize the Mobile and Computer Website Integrated College Content Management System}

The mobile and computer website integrated college content management system can satisfy the colleges demand. The system includes the following four key technology areas.

(1) Mobile and computer website integration

Through the realization of mobile website build websites and computer website, and later the site management.

(2) Content management

Achieve website content online editor, online publishing and other functions, real-time update and manage website content, reducing site management costs.

(3) Content Search

We can achieve a variety of ways, such as title search, text search or a third-party search engines, the website.

(4) Page displays template

Using template technology, the non-professional and technical personnel can also publish reasonable and beautiful layout of the page. You only need to modify the page template. It can be completed on site style adjustments.

\section{Conclusion}

College website has been unable to meet the growing needs of mobile Internet. Mobile and computer website integrated college online content management system solves the drawbacks of traditional college website system construction and management. The system can speed up the construction of college information.

\section{Acknowledgement}

This research was supported by the funds from:

1) Fujian Province Education Department 2012JK Project (Number JK2012041): The Applications of Cloud Computing and Internet of Things in the Enterprise Information Public Service Platform.

2) Construction Funds of Master Degree Awarded Unit of Quanzhou Normal University.

3) Construction Funds of High Educational Engineering Research Center of of Fujian Pronvince for E-Commerce Intelligent Based on Cloud Computing and Internet of Things.

4) The Construction of Key Projects of Fujian Province Serving Haixi "Haixi Port Logistics Information Platform Construction", Project Number: A103.

5) Science Plan Project of Fujian, Project Number: $2013 R 0087$.

6) Science and Technology Plan Project of Quanzhou Normal University, Project Number: 2014KJ04. 
7) Young Core Teacher of Quanzhou Normal University.

8) Fujian Province Education Department 2013 A Class Science and Technology Project (Project Number JA13271): The Development of College Online Content Management System Integrated with SEO and SMO.

9) 2014 College Students Innovation and Entrepreneurship Training Plan Project of Fujian Province, Project Number: 201410399046.

10)2014 College Students Innovation and Entrepreneurship Training Plan Project of Quanzhou Normal University, No. 67: Difficulties And Countermeasures Of Network Marketing Of Quanzhou Small And Medium-Sized Enterprise.

11)2014 College Students Innovation and Entrepreneurship Training Plan Project of Quanzhou Normal University, No. 66: Design of College Intelligent System Integrated Mobile and Computer Website.

\section{References}

[1] Zhou Fang. Design and Implementation of Template Technology on Website Content Management System [D]. Beijing Jiaotong University, 2009.

[2] Liu Kunfeng. University Research and Implementation of Content Management System [D]. Hebei University of Technology, 2011.

[3] Mayan Ting. Design and Implementation of News Network Platform Content Management System [D]. South China University of Technology, 2011.

[4] Li Weili1, Gao Bao1, Xu Xing. Content Management System and University Information System [J]. Experimental Technology and Management, 2011, 05: 244-246.

[5]Wang Jing. College Content Management System (CMS) Application And Research [J]. Silicon Valley, 2012, 01: 98-99.

[6] Wang Yiqun. Role of Content Management System in Colleges and Universities in Information Technology [J]. Value Engineering, 2013,14: 232-233.

[7] Sun Hong. University Website Content Management System [J]. Technology Wind, 2013, 12: 196. 